\title{
DISCUSSION
}

\section{Preconsolidation pressure from piezocone tests in marine clay}

\author{
J.-M. KONRAD and K. T. LAW (1987). Géotechnique 37, No. 2, 177-190
}

\author{
P. W. Mayne, Research Assistant, Cornell Uni- \\ versity
}

The proposed effective stress path interpretation of an advancing piezocone provides an interesting means for profiling the in situ stress history of clay deposits. This Writer has pursued this topic from both a total stress approach (Mayne, 1987) and an effective stress method (Mayne \& Bachus, 1987). For an assumed elastic-plastic behaviour of soil, cavity expansion theory may be used to relate the degree of overconsolidation to the measured excess pore pressure.

The excess pore pressures $\Delta u$ observed in piezocone tests reflect the increases in octahedral and shear stresses due to cone penetration. The response is similar to that for a driven pile in clay (Randolph, Carter \& Wroth, 1979). It may also be shown that for OCR's of the order of 1 to 10 , shear-induced pore pressures typically contribute less than 23\% (Baligh, 1986) of the observed pore pressures. Consequently, a first order approximation for piezocones with the pore pressure measured just behind the tip and advanced into lightly to moderately overconsolidated clays may be obtained assuming cylindrical cavity expansion

$$
\Delta u=C_{\mathrm{u}} \ln \left(G / C_{\mathrm{u}}\right)
$$

where $C_{u}=$ undrained shear strength, $G=$ shear modulus, and $G / C_{\mathrm{u}}=$ rigidity index.

Dividing both sides of eqn (1) by the effective preconsolidation pressure $\left(\sigma_{p}^{\prime}\right)$ and rearranging terms

$$
\sigma_{\mathrm{p}}^{\prime}=\frac{\Delta u}{\left(C_{\mathrm{u}} / \sigma_{\mathrm{p}}{ }^{\prime}\right) \ln \left(G / C_{\mathrm{u}}\right)}
$$

The normalized strength ratio $\left(C_{\mathrm{u}} / \sigma_{\mathrm{p}}{ }^{\prime}\right)$ is a characteristic parameter used to describe clays (Larsson, 1980) yet it depends strongly on the mode of shear. Adopting triaxial compression as the relevant mode (Baligh, 1986) the behaviour of St. Alban clay may be considered as representative of the Champlain clays. Data from Leroueil, Tavenas, Brucy, La Rochelle \& Roy (1979) indicate $C_{\mathrm{u}} / \sigma_{\mathrm{p}}{ }^{\prime}=0.37$ and $G / C_{\mathrm{u}}=300$ for intact specimens. Consequently, eqn (2) would suggest $\sigma_{\mathrm{p}}{ }^{\prime}=\Delta u / 2 \cdot 1$

${ }^{\mathrm{p}}$ For the marine clays of eastern Canada, Fig. 1 suggests that the preconsolidation pressure may be approximately related to the excess pore pressures by

$$
\sigma_{\mathrm{p}}{ }^{\prime}=\Delta u / 2 \cdot 5
$$

The data from the five sites reported by the Authors were processed in a manner similar to that described by Wroth (1984). Additional piezocone data were obtained from Tavenas (1981); Tavenas, Leroueil \& Roy (1982) and Roy, Tremblay, Tavenas \& La Rochelle (1982).

The inclusion of shear-induced pore pressures in eqn (2) results in an improved match with available piezocone data, yet offers a more complicated expression between $\sigma_{\mathrm{p}}{ }^{\prime}$ and $\Delta u$.

\section{G. Kabir \& Professor A. J. Lutenegger, Clark- son University}

The Authors suggest that a simple model can be used to interpret the stress history of marine clay deposits during the quasi-static penetration of a piezocone. A relationship has been presented between the effective vertical yield stress $\sigma_{\mathrm{yc}}{ }^{\prime}$ mobilized along the cone axis during penetration and the difference between the induced total vertical stress in the soil and the total generated pore pressure. The Authors suggest that the induced total vertical stress and the total generated pore pressure may be obtained from the piezocone and are inferred from the cone resistance $q_{\mathrm{c}}$ and measured pore pressure at the base of the cone $u_{t}$, respectively. The Authors' model was applied to experimental results obtained at five test sites in the St. Lawrence Lowlands in eastern Canada with OCR ranging from 1.3 to 4.8 . These data were then interpreted using the proposed model and the Authors concluded that the ratio $\sigma_{\mathrm{yc}}{ }^{\prime} / \sigma_{\mathrm{pv}}{ }^{\prime}$ is preferred in estimating OCR instead of relating $B_{\mathrm{q}}$ to OCR, as is morc commonly done.

The Writers recently conducted piezocone tests in similar marine clays in northern New York (Lutenegger \& Kabir, 1987) and have applied the Authors' model to re-evaluate the oedometric yield stress at three different test sites. A detailed geotechnical investigation at the Massena High School (MHS) site, shows that the soil profile consists of $\approx 2 \mathrm{~m}$ of weathered, desiccated crust of stiff silty clay underlain by a thick deposit of soft marine clay. The clay is about $10 \mathrm{~m}$ thick and is 


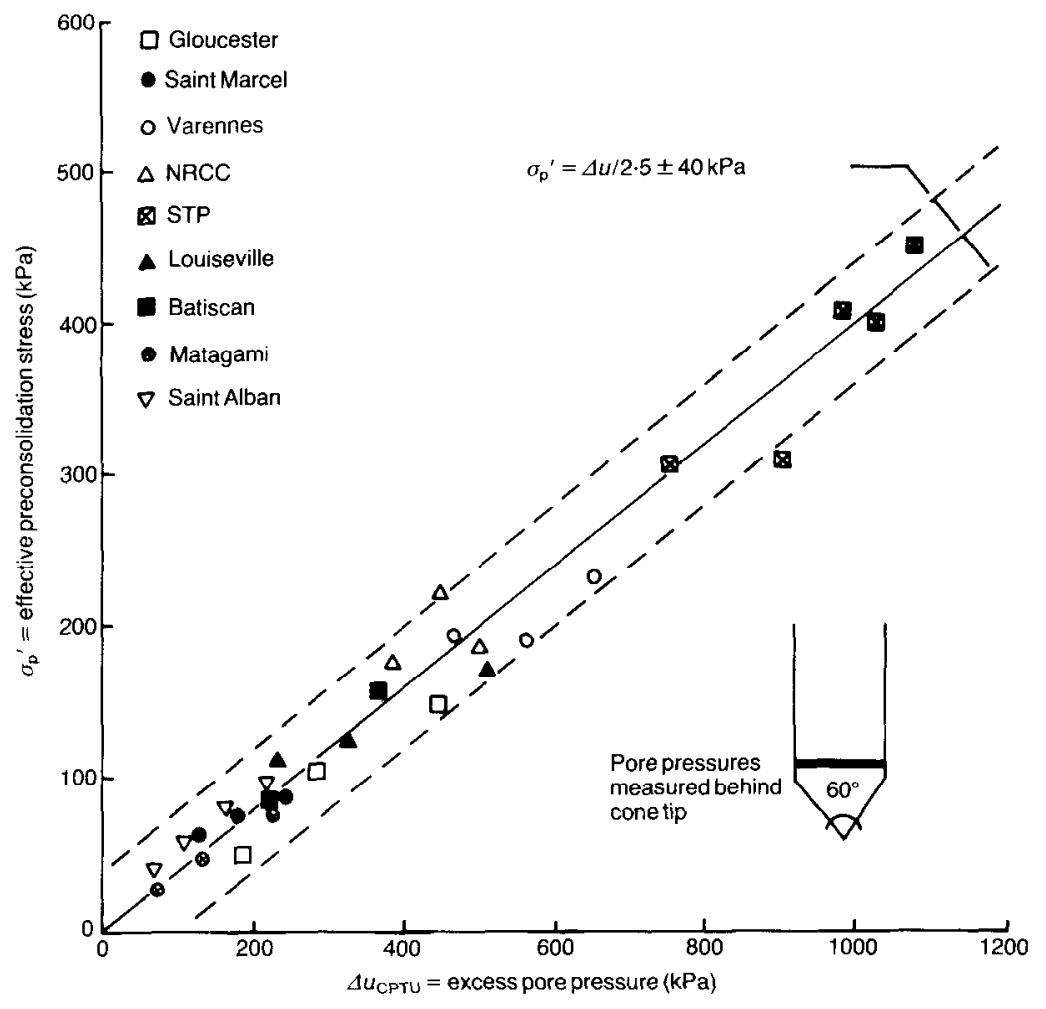

Fig. 1. Observed direct trend between the effective preconsolidation pressure and measured excess pore pressure from piezocones advanced into clays of eastern Canada
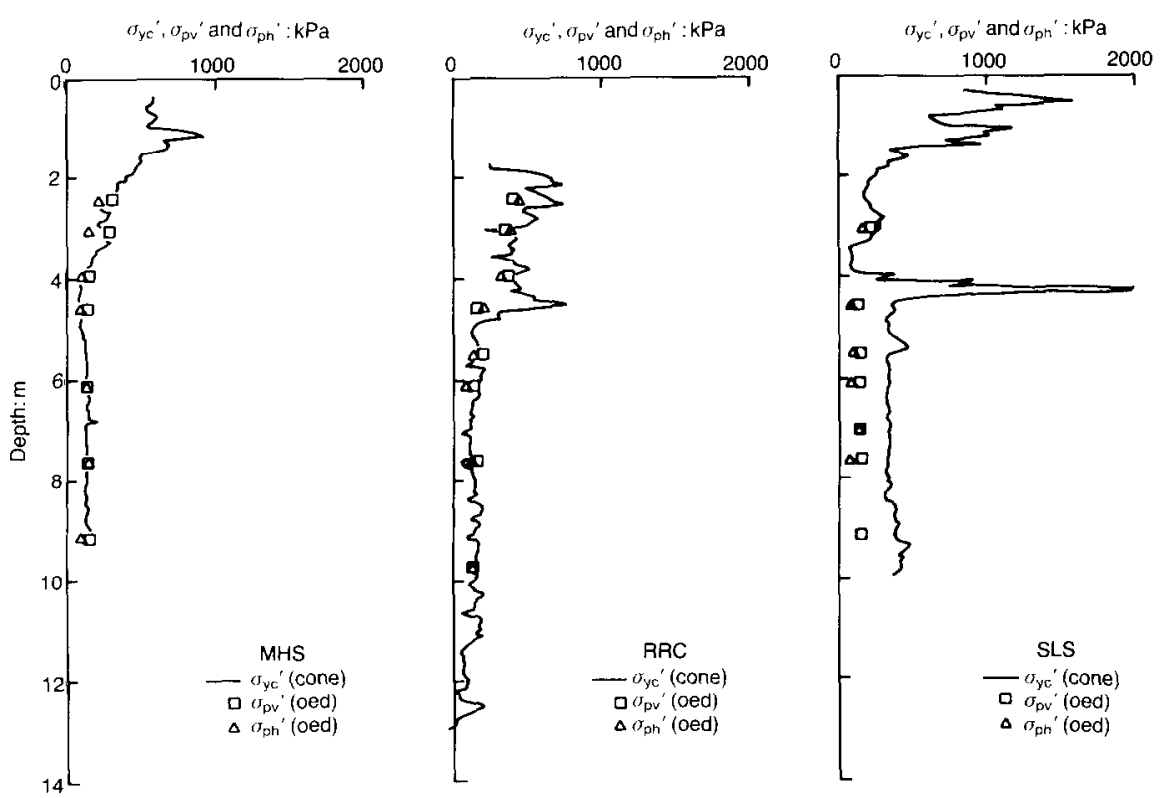

Fig. 2. Estimated preconsolidation stress from piezocone tests at the MHS, RRC and SLS sites 

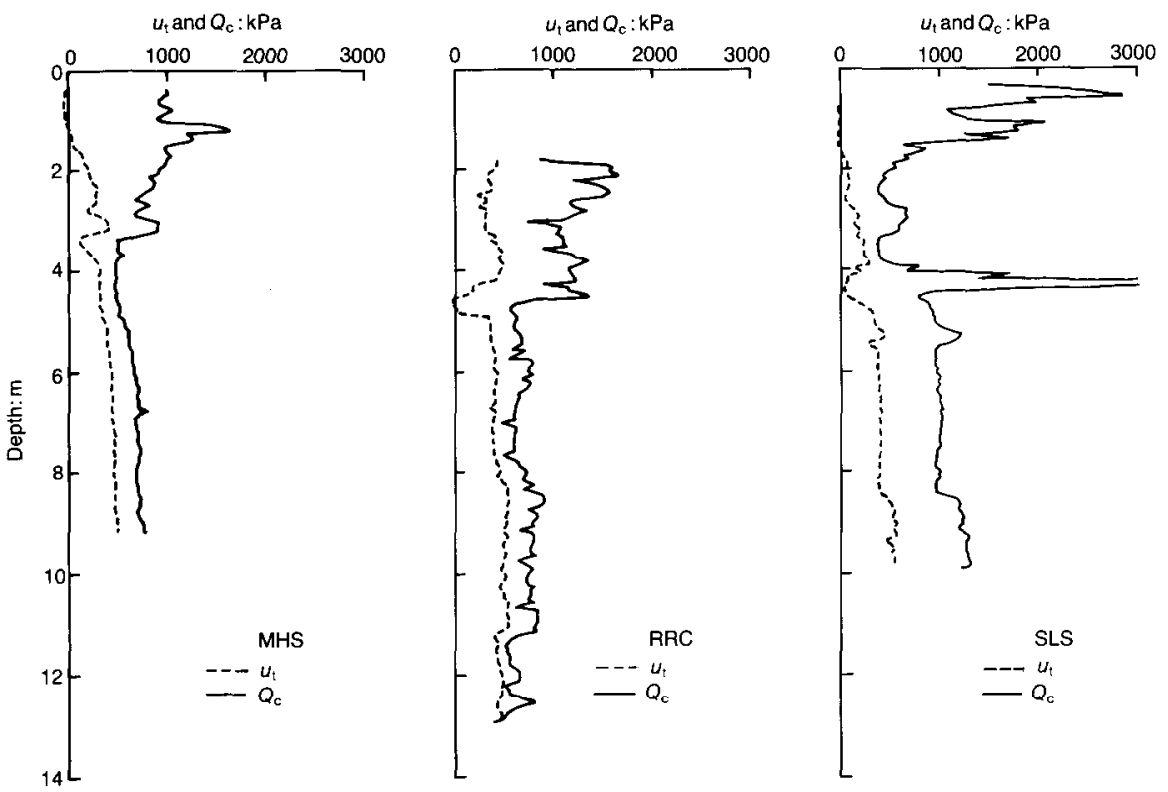

Fig. 3. Piezocone profile at the MHS, RRC and SLS sites

underlain by glacial till. The Racquettc River Cemetery (RRC) site has a subsoil profile which consists of a 2-2.5 m surficial deposit of sand which overlies up to $11.6 \mathrm{~m}$ of soft marine clay which is itself underlain by glacial till. The SLS site is near the Snell Lock of the St. Lawrence Seaway in Massena. The subsoil profile consists of greyish silty clay up to a depth of $12.2 \mathrm{~m}$ underlying a $1.52 \mathrm{~m}$ thick greyish brown silt. The piezocone used has the pore pressure element located $5.7 \mathrm{~mm}$ behind the base of a standard $35 \cdot 7 \mathrm{~mm}$ dia., $60^{\circ}$ cone.

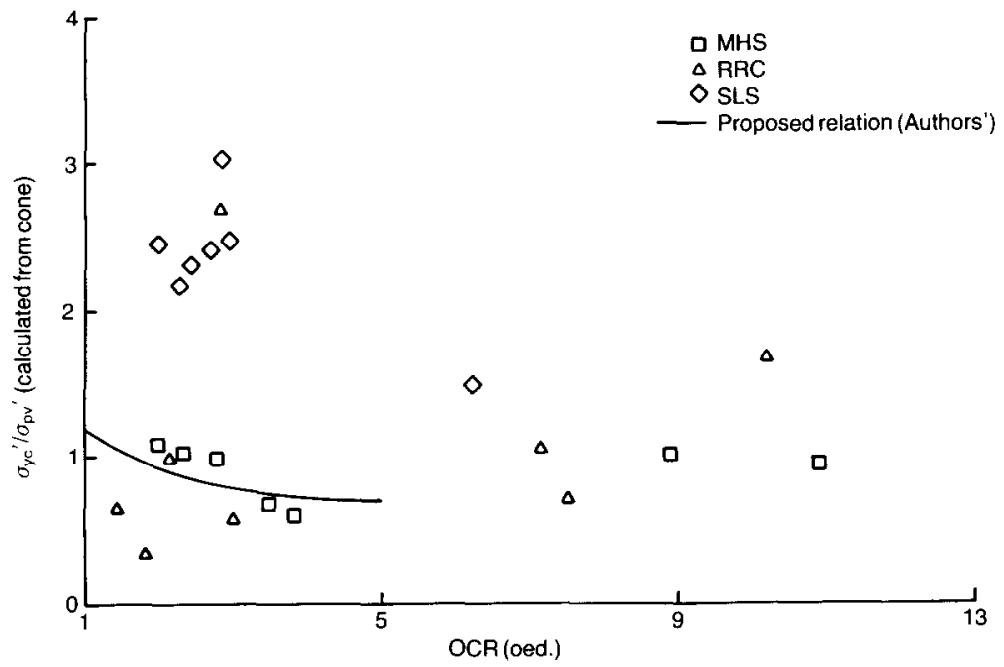

Fig. 4. Relationship between $\sigma_{\mathrm{yc}}{ }^{\prime} / \sigma_{\mathrm{pv}}{ }^{\prime}$ and OCR for the three sites
Figure 2 shows the variation of piczocone determined $\sigma_{\mathrm{pv}}{ }^{\prime}$ using the Authors' technique and $\sigma_{\mathrm{p}}{ }^{\prime}$ determined from vertical and horizontal stress controlled oedometer tests at the three sites. In order to calculate $\sigma_{p}{ }^{\prime}$, the friction coefficient $M$ was taken as unity. The estimated values of $\sigma_{p}{ }^{\prime}$ using the Authors' model from the piezocone compares fairly well with the laboratory determined values at the MHS and RRC sites, but it appears that their model is less accurate in predicting $\sigma_{p}{ }^{\prime}$ at the SLS site, with the piezocone values significantly higher than the laboratory 

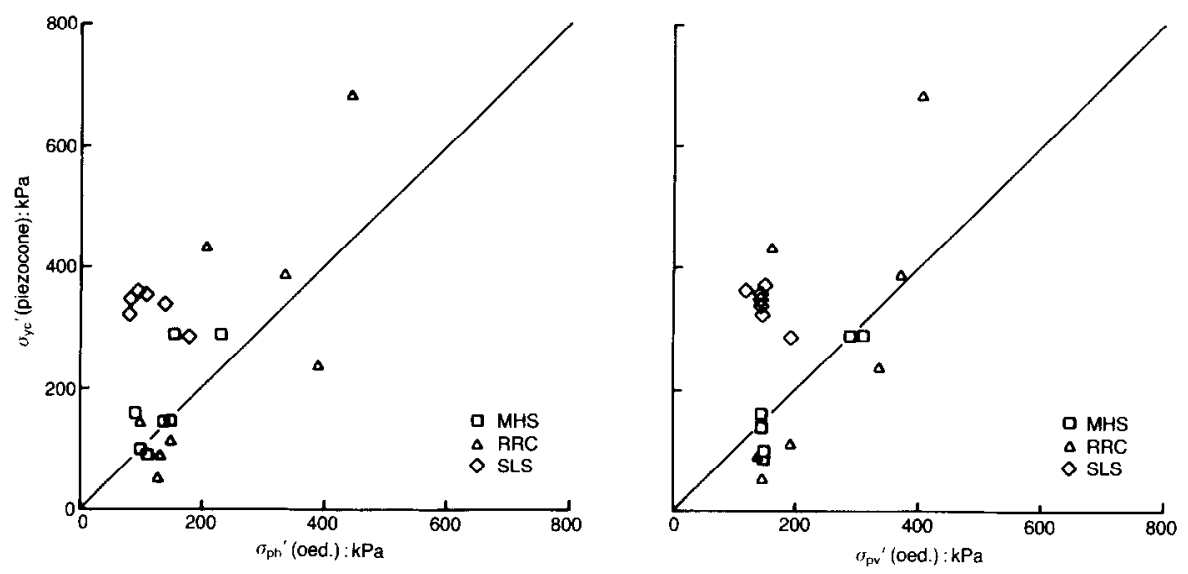

Fig. 5. $\sigma_{y c}{ }^{\prime}$ against horizontal and vertical preconsolidation stress

determined values. While this site is geologically similar to the other two sites, grain size analyses indicate that the sand content is significantly higher than at MHS or RRC. The profiles of $q_{c}$ and $u_{t}$ for the three sites are shown in Fig. 3.

In comparison to the MHS and RRC sites, it can be seen that the SLS data show generally higher values of $q_{\mathrm{c}}$. In sandy soils, $q_{\mathrm{c}}$ is relatively larger and $u_{t}$ is relatively smaller than clays because of differences in stiffness, and there is a possibility that some drainage may occur and that therefore the cone penetration is not undrained. Thus, the difference $\left(q_{c}-u_{t}\right)$ would be higher and the corresponding prediction of $\sigma_{p}{ }^{\prime}$ using the Authors' model would be higher.

Figure 4 shows a comparison between the ratio $\sigma_{\mathrm{yc}}{ }^{\prime} / \sigma_{\mathrm{pv}}{ }^{\prime}$ and $\mathrm{OCR}$ for the three sites. A large range is observed at low OCR whereas it becomes narrower at high OCR. This large scattering of $\sigma_{\mathrm{yc}}{ }^{\prime} / \sigma_{\mathrm{pv}}{ }^{\prime}$ contradicts the Authors' prediction. As can be seen from Fig. 3, the Authors' proposed relationship of $\sigma_{\mathrm{yc}}{ }^{\prime} / \sigma_{\mathrm{pv}}{ }^{\prime}$ with OCR falls within a relatively small zone. At the SLS site, for most of the data points, OCR ranges from 1.5 to
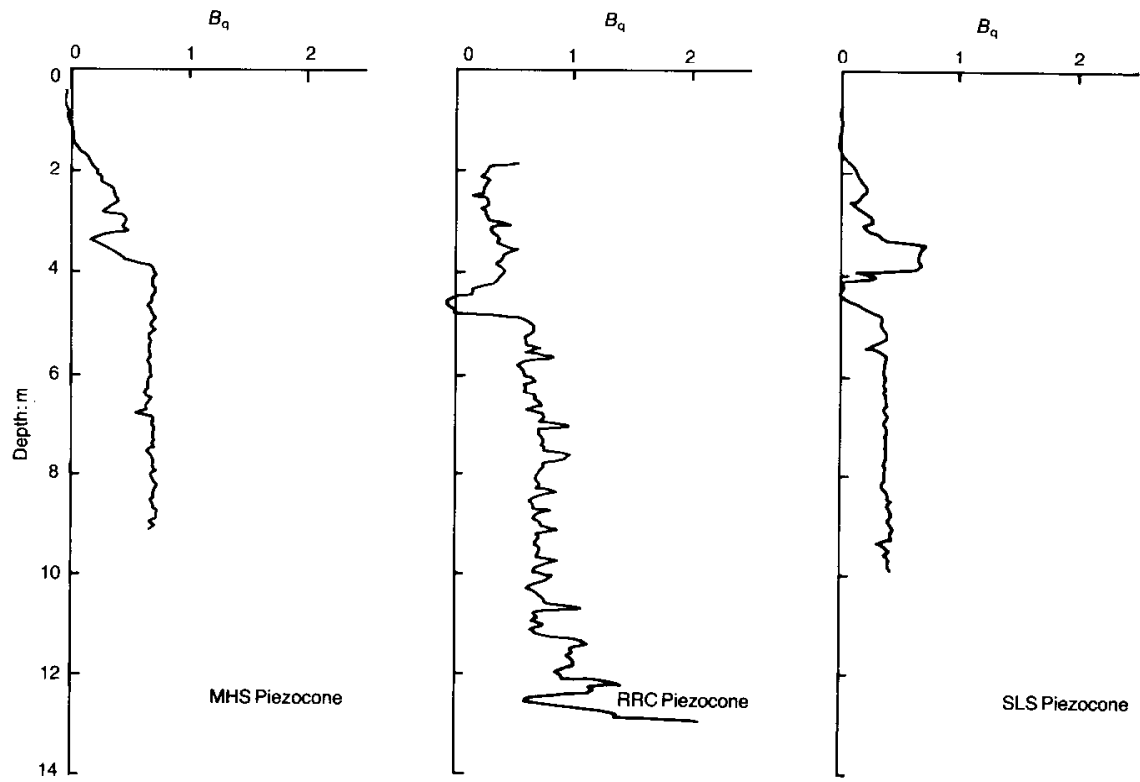

Fig. 6. Depth against $B_{\mathrm{q}}$ for all three sites 
3.0 , but the ratio $\sigma_{\mathrm{yc}}{ }^{\prime} / \sigma_{\mathrm{pv}}{ }^{\prime}$ is around $2 \cdot 5$. In the Writers' opinion, the ratio $\sigma_{\mathrm{yc}}{ }^{\prime} / \sigma_{\mathrm{pv}}{ }^{\prime}$ not only related to OCR but also related to rigidity index, grain size, soil plasticity and sensitivity. Therefore, a detailed analysis is required which would incorporate all of these factors in calculating the yield stress from piezocone data. Additionally, a database with a number of soil types would be required to correlate the parameter $\sigma_{\mathrm{yc}}{ }^{\prime} / \sigma_{\mathrm{pv}}{ }^{\prime}$ with OCR. The relationships of $\sigma_{y c}{ }^{\prime}$ from the piczocone with laboratory determined vertical and horizontal $\sigma_{\mathrm{p}}{ }^{\prime}$ are shown in Fig. 5. For MHS and RRC, the $\sigma_{\mathrm{yc}}$ ' is slightly higher than $\sigma_{\mathrm{pv}}{ }^{\prime}$ and $\sigma_{\mathrm{ph}}{ }^{\prime}$, but for SLS, the $\sigma_{\mathrm{yc}}{ }^{\prime}$ is substantially higher. In the Writers' opinion, while the model may be reasonably accurate in normally and lightly overconsolidated cohesive soil, a more detailed analysis is required for other soil types.

In Fig. 6, the parameter $B_{\mathrm{q}}$ is plotted with depth for each site. For MHS, the value of $B_{\mathrm{q}}$ below $4 \mathrm{~m}$ depth is almost constant at 0.70 . For $\mathrm{RRC}, B_{\mathrm{q}}$ is a constant value of 0.75 below $5 \mathrm{~m}$. For the SLS site, it is constant below $5 \mathrm{~m}$ depth at a value of 0.40 . These data would suggest that $B_{\mathrm{q}}$ attains a constant value in normally consolidated soils and the magnitude depends primarily on soil type and in situ stress condition. However, the Writers suggest that $B_{\mathrm{q}}$ would be more valuable if $\sigma_{\text {oct }}$ were used instead of $\sigma_{\mathrm{v} 0}$.

The Writers have observed that during piezocone penetration in overconsolidated soils, the measured pore pressures behind the cone base show a time lag to reach a maximum value after interruption of the sounding, i.e. the measured pore pressure during penetration is not the maximum generated pore pressure. Senneset, Janbu \& Svanø (1982) proposed the parameter $B_{\mathrm{q}}$ to correlate with OCR. Robertson \& Campanella (1983) postulated that the relationship between pore pressure and OCR will be influenced by variations in soil plasticity and sensitivity since the excess pore pressure is a function of rigidity index, $I_{\mathrm{R}}$. Fig. 7 shows the relationship of $B_{\mathrm{q}}$ calculated by using initial and maximum pore pressure with measured OCR. $B_{\text {a }}$ calculated using initial pore pressure shows a better agreement with OCR, but at low OCR large scattering is observed. As expected, $B_{\mathrm{q}}$ decreases as OCR increases. One important aspect of $B_{\mathrm{q}}$ is that it can be used in the negative to represent sandy soils.

Because of the time lag phenomenon in overconsolidated soils, the difference $\left(q_{c}-u_{t}\right)$ increases and thus the value of predicted $\sigma_{p}$ ' increases. To obtain accurate values of $\sigma_{\mathrm{p}}{ }^{\prime}$ using the Authors' model, maximum pore pressure in the failure zone is required. In order to obtain the maximum pore pressure in a failure zone, a correction factor is needed for pore pressures mea-
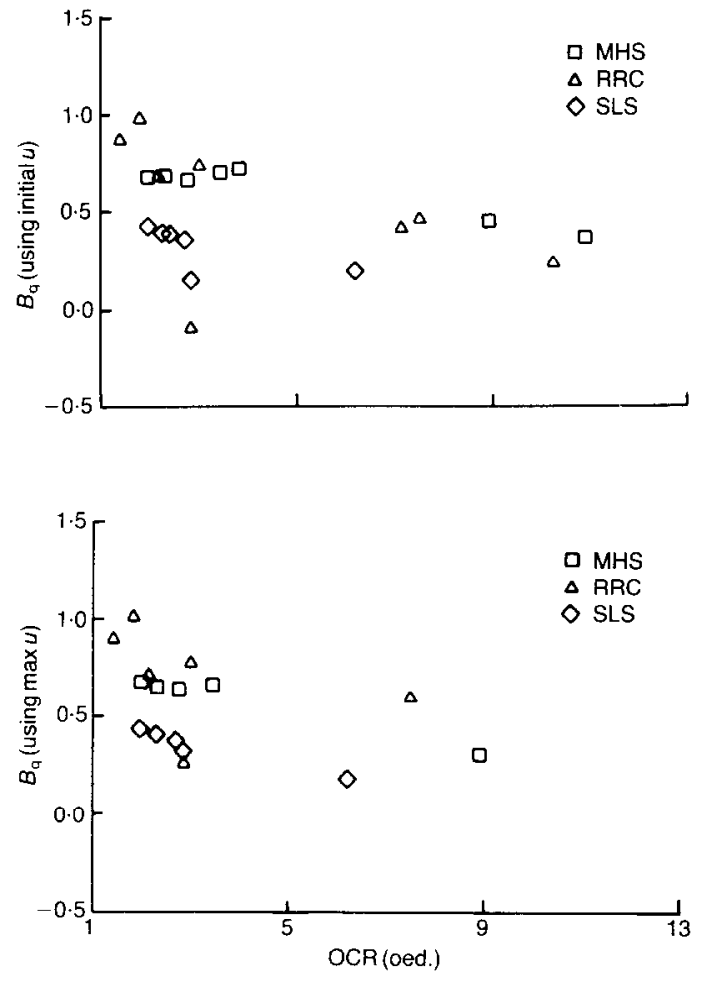

Fig. 7. $B_{\mathrm{q}}$ against $\mathrm{OCR}$ for all three sites

sured behind the base. Generally the maximum pore pressure is generated at the cone tip. As discussed by Campanella, Robertson \& Gillespie (1986), in normally consolidated insensitive clays and silts the pore pressure at the cone tip is usually $15-20 \%$ higher than the pore pressure measured behind the base. According to Roy, Tremblay, Tavenas \& Rochelle (1982) this factor is in the range of $1-1 \cdot 1$ for sensitive clay. In the Writers' opinion, in normally consolidated soils the factor should bc 1.0 . In overconsolidated soils, if the pore pressure is measured behind the cone base, the maximum pore pressure is about 1.22 times the initial pore pressure.

A plot of $\left(\sigma_{v 0}, u_{0}\right)$ against $\left(q_{c}, u_{t}\right)$ for all three sites is shown in Fig. 8.

In normally and lightly overconsolidated soils (OCR $\leq 2.0$ ) it is found that $q_{\mathrm{c}}, u_{\mathrm{t}}$ always fall within a small band, i.e. the failure condition lies close to the failure stress path as assumed by the Authors. However, in the overconsolidated zone, $q_{\mathrm{c}}, u_{\mathrm{t}}$ shows a large scattering, apparently depending on stress condition and soil type. It is obvious that the failure condition, as well as the stress path, is not the same in overconsolidated soils. In the Writers' opinion, a rigorous analysis is required to take care of the stress condition. 

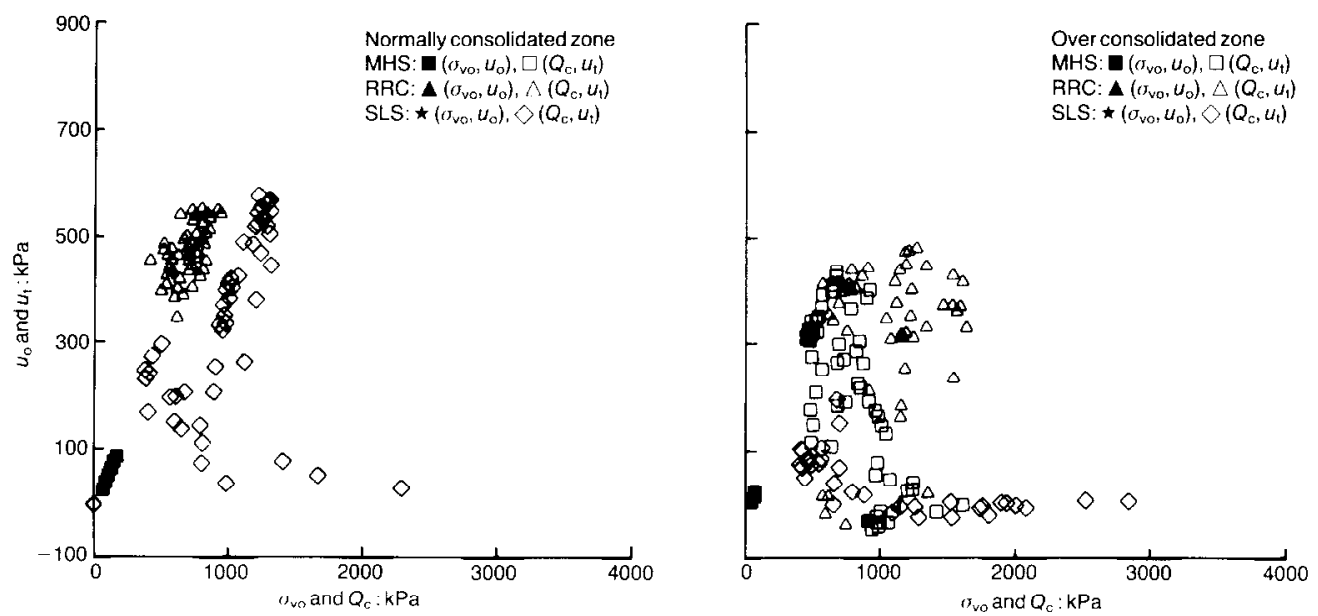

Fig. 8. $\sigma_{v 0}$ and $q_{\mathrm{c}}$ against $u_{0}$ and $u_{\mathrm{t}}$ for the MHS, RRC and SLS sites

P. K. Robertson, J. A. Howie, J. P. Sully, D. G. Gillespie \& R. G. Campanella, University of British Columbia, Vancouver

The Authors have introduced some interesting ideas on determining stress history in clays from piezocone tests (CPTU). The observation that the pore pressure parameter $B_{\mathbf{q}}$ is not uniquely related to OCR for all clays is consistent with previous observations (Jamiolkowski, Ladd, Germaine \& Lancellotta, 1985; Robertson, Campanella, Gillespie \& Grieg, 1986; Battaglio, Bruzzi, Jamiolkowski \& Lancellotta, 1986).

Figure 9 represents a summary of $B_{\mathrm{q}}$ against OCR data given by Robertson et al. (1986). Included are the data presented by the Authors for the five sites in eastern Canada. The distribution of the Authors' data is consistent with the trends shown in Fig. 9.

The method proposed by the Authors for the determination of the vertical effective yield stress during cone penetration $\sigma_{\mathrm{yc}}{ }^{\prime}$ and then $\sigma_{\mathrm{p}}{ }^{\prime}$ from oedometer tests, at first appears somewhat complex. However, on closer examination several important aspects become apparent.

The proposed method relies on several assumptions regarding measured and calculated parameters which produce

$$
\begin{gathered}
u_{\mathrm{m}}=\alpha u \\
\sigma_{\mathrm{yc}}{ }^{\prime}=\frac{q_{\mathrm{t}}-\alpha u}{1+M \tan \phi^{\prime} \cot \theta}
\end{gathered}
$$

where $u_{\mathrm{m}}=$ assumed average pore pressure on face of penetrating tip, $u=$ measured pore pressurc immediately behind the tip, $M=$ friction factor for the soil acting on the cone surface, $\phi^{\prime}=$ effective friction angle of the normally consolidated soil, $\theta=$ half apex angle of the cone tip (usually $30^{\circ}$ ) and $q_{\mathrm{t}}=$ measured cone resistance corrected for unequal end area effects.

The parameters $q_{\mathrm{t}}$ and $u$ are measured, whereas $\alpha, M$ and $\phi^{\prime}$ have to be estimated independently. The factor $\alpha$ relates the measured pore pressure behind the tip to that along the face. The Authors suggest that $\alpha=1$ should be assumed, with a maximum upper bound value of $1 \cdot 33$.

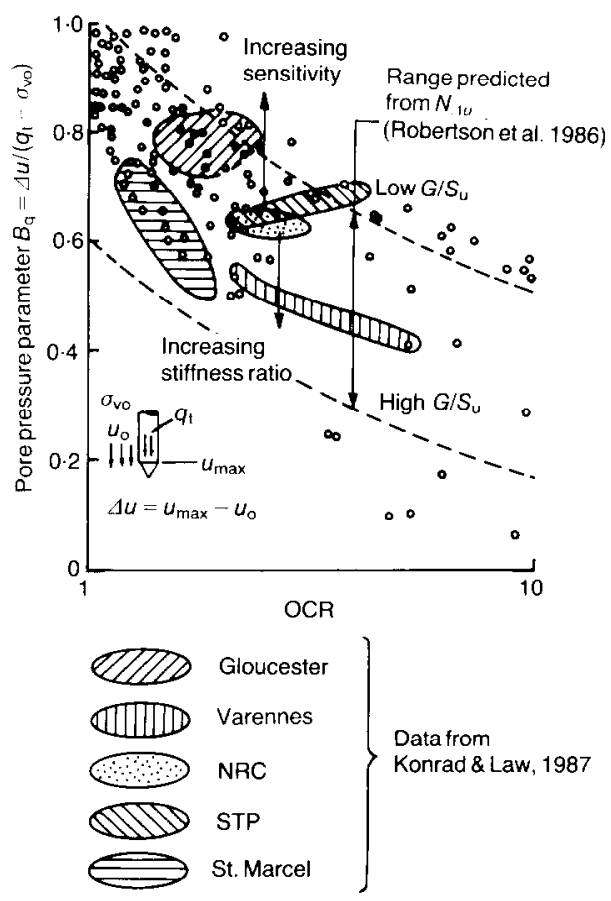

Fig. 9. Comparison of various $B_{\mathrm{q}}$ data against $\mathrm{OCR}$ (Robertson et al., 1986) 


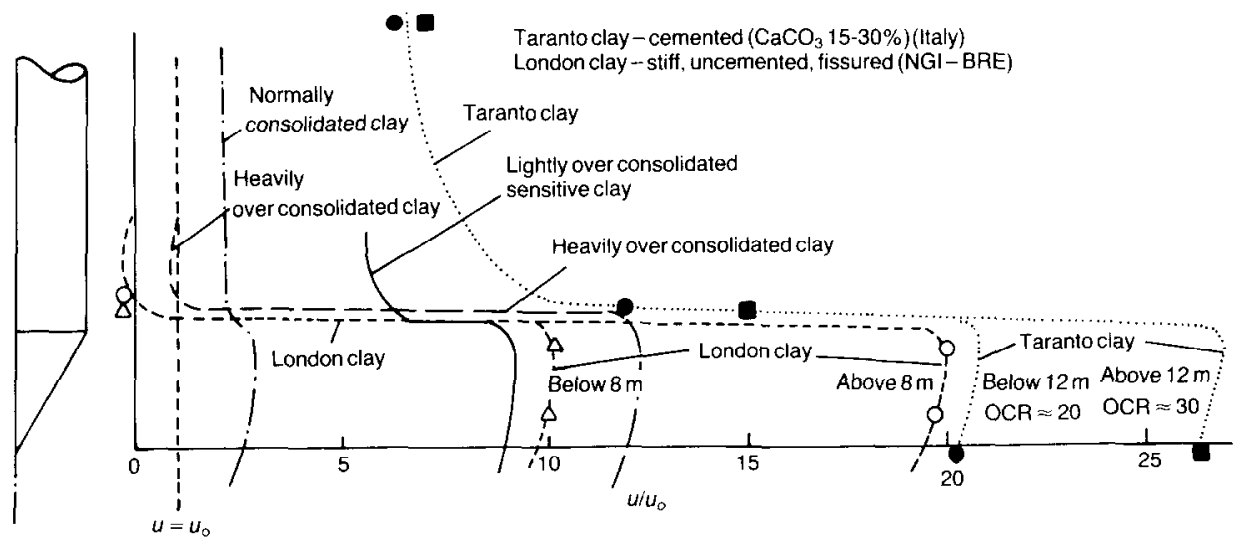

Fig. 10. Conceptual pore pressure distribution in saturated soil during CPTU based on field measurements (Robertson et al., 1986)

Figure 10 shows a summary of pore pressure data measured at different locations on a penetrating cone. This clearly shows that the difference between the pore pressures measured on the face and behind the tip can be very large and appears to increase with increasing OCR.

Figure 11 shows additional data (from Sully, Campanella, Robertson \& Gillespie, 1988) to illustrate that $x$ appears to be dependent on the

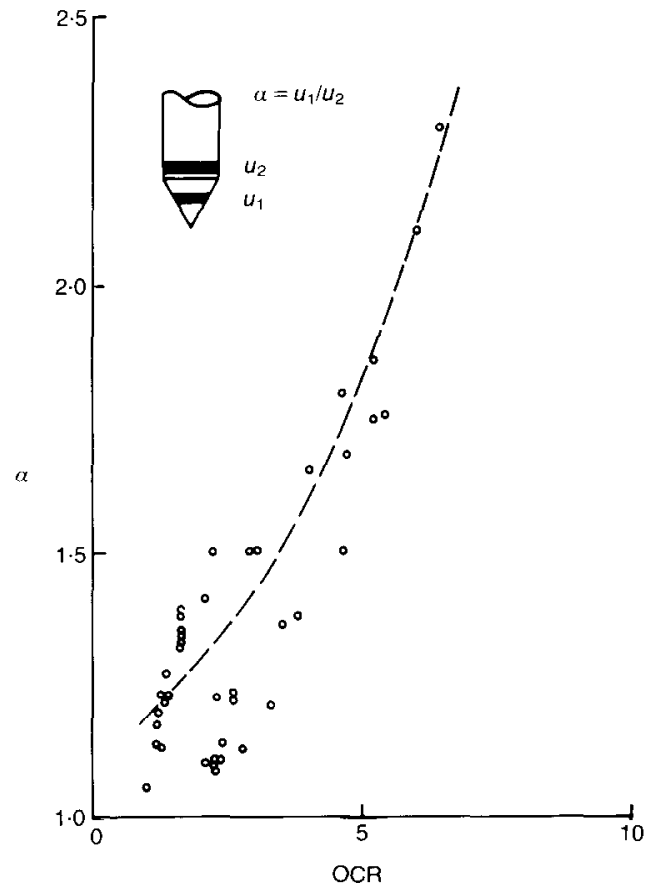

Fig. 11. Variation of $\alpha$ with OCR for lightly to moderately overconsolidated cohesive soils
OCR of the soil As the OCR increases, $\alpha$ tends to infinity as the pore pressure behind the tip reduces to very small values. As the pore pressure behind the tip may attain negative values with larger values of OCR, the $\alpha$ factor definition becomes problematical.

From Fig. 11 it also appears that $\alpha=1 \cdot 2$ would appear more appropriate for Champlain Sea sensitive clays similar to those reviewed by the Authors. A variation in $\alpha$ from 1.0 to 1.2 would have a considerable influence on the estimated $\sigma_{\mathrm{yc}}{ }^{\prime}$.

While the Authors assume that $\alpha=1, M=1$ and $\theta=30^{\circ}$, no details are given concerning the relevant value of $\phi^{\prime}$; whether peak or constant volume. If a value of $\phi^{\prime} \simeq 28^{\circ}$ is sclected based on pile data (Konrad \& Roy, 1987), equations (4) and (5) suggest that

$$
\sigma_{y c}{ }^{\prime} \approx \frac{q_{1}-u}{2}
$$

If the OCR is approximated as

then

$$
\sigma_{\mathrm{yc}}{ }^{\prime} / \sigma_{\mathrm{vo}}{ }^{\prime} \approx \mathrm{OCR}
$$

$$
\frac{q_{\mathrm{t}}-u}{\sigma_{\mathrm{v0}}{ }^{\prime}} \approx 2(\mathrm{OCR})
$$

The Authors stress that in soft soils $q_{\mathrm{t}}$ can be sensitive to measurement errors. Typically, $q_{\mathrm{t}}$ and $u$ are accurate to within $0.5 \%$ of full-scale output. For a $25 \mathrm{kN}$ tip capacity cone (as recommended by the Authors, max. $q_{\mathrm{t}}=25000 \mathrm{kN} / \mathrm{m}^{2}$ ) the error in $q_{\mathrm{t}}$ can be $\pm 125 \mathrm{kN} / \mathrm{m}^{2}$ (i.e. $25 \%$ of the measured value for $q_{\mathrm{t}}=500 \mathrm{kN} / \mathrm{m}^{2}$ ). The error in $u$ for a typical $1000 \mathrm{kN} / \mathrm{m}^{2}$ capacity pressure transducer can be in the order of $\pm 5 \mathrm{kN} / \mathrm{m}^{2}$ (i.e. $1 \%$ of the measured value for $u=500 \mathrm{kN} / \mathrm{m}^{2}$ ). Consequently, even for low capacity cones and 


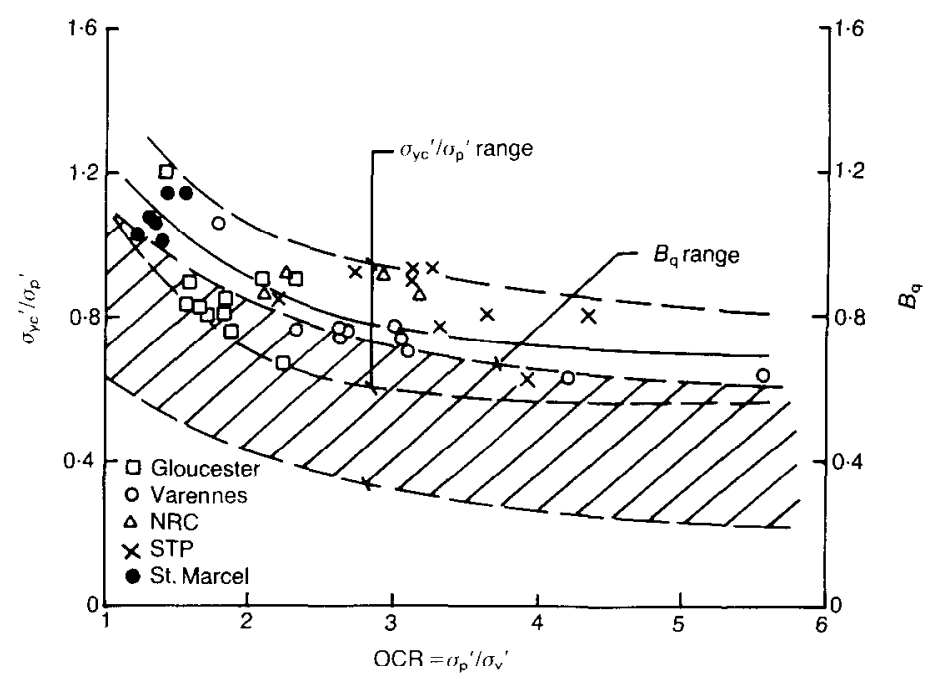

Fig. 12. Comparison between $B_{q}$ and $\sigma_{y c}{ }^{\prime} / \sigma_{p}{ }^{\prime}$ relationships with $O C R$

careful test procedures, the value of $q_{\mathrm{t}}-u$ can be subject to serious errors, especially in very soft soils.

Senneset et al. (1982) suggested a similar approach but for the determination of undrained shear strength $S_{\mathrm{u}}$ where

$$
S_{\mathrm{u}}=\frac{q_{\mathrm{t}}-u}{N_{\mathrm{KE}}}
$$

Senneset et al. (1982) proposed that $N_{\mathrm{KE}}=9$ with a likely variation of \pm 4 . Lunne, Christoffersen \& Tjelta (1985) and Robertson et al. (1986) showed that $N_{\mathrm{KE}}$ varied from 1 to 12 and appeared to correlate with OCR.

It is commonly appreciated that

$$
\frac{S_{\mathrm{u}}}{\sigma_{\mathrm{v} 0}{ }^{\prime}}=A(\mathrm{OCR})^{\mathrm{m}}
$$

For many soft, sedimentary clays of low to moderate plasticity and where $S_{\mathrm{u}}$ is determined by the field vane test, the following values apply (Jamiolkowski et al. 1985) for OCR < 10: $A=0.23 \pm 0.04 ; m=1.03 \pm 0.26$. Therefore

$$
S_{\mathrm{u}} / \sigma_{\mathrm{vo}}{ }^{\prime} \approx 0.23 \text { (OCR) }
$$

Using the approach by Senneset et al. (1982) and assuming $N_{\mathrm{KE}}=9$ and combining with equation (11) the following approximate relationship results

$$
\frac{q_{\mathrm{t}}-u}{\sigma_{\mathrm{vo}}{ }^{\prime}} \approx 2 \cdot 07(\mathrm{OCR})
$$

Equation (12) (from Senneset $e t$ al.) is virtually the same as equation (8), based on the Authors' approach.
However, experience with the method of Senneset $e t$ al. has shown that the 'effective' cone resistance $q_{\mathrm{t}}-u$ is unreliable and insensitive, especially in soft clays where the measured pore pressure $u$ is often approximately $90 \%$ of the corrected cone resistance $q_{\mathrm{t}}$.

The problems of accuracy associated with the measurement of cone resistance in soft clays has led to methods to determine $S_{\mathrm{u}}$ and OCR directly from CPTU pore pressure data (Campanella, Robertson, Gillespie \& Grieg, 1985; Sully, Campanella \& Robertson, 1987) without incorporating $q_{1}$.

Figure 12 presents the combined data from the Authors' figures 9 and 19 and the Writers' Fig. 9. It can be seen from Fig. 12 that the Authors' proposed correlation for $\sigma_{y c}{ }^{\prime} / \sigma_{p}^{\prime}$ is only marginally better than that obtained with the existing $B_{\mathrm{q}}$ correlation. In both cases the scatter is large in terms of OCR.

It would appear therefore, that the Authors' proposed relationship between OCR and $\sigma_{y c}{ }^{\prime} / \sigma_{p}{ }^{\prime}$ suffers from many of the same restrictions as existing pore pressure parameter $B_{\mathrm{q}}$-OCR correlations.

If the pore pressure is measured directly on the face of the cone $\left(u_{\mathrm{m}}\right)$ the Authors' proposed method remains insensitive, especially in soft clays, since $q_{1}-u_{\mathrm{m}}$ is still a very small value.

The Authors' idealized approach to the mechanism taking place during cone penetration represents an interesting insight into the process. However, the Writers feel that it is important to realize the inherent limitation of the CPTU and to treat any interpretation, theoretical or empirical, within the limits of the equipment and the 
assumptions related to soil response. The CPTU is an excellent test for stratigraphic logging and can provide good estimates of some geotechnical parameters, but soil response due to cone penetration is extremely complex and depends on many variables, such as initial stress state, stress and strain history, stiffness, sensitivity, and structure.

\section{Authors' reply}

Messrs. Mayne, Kabir, Lutenegger and the panel led by Dr Robertson are to be thanked for preparing discussions with valuable additional information.

Mayne presents a summary of piezocone data in marine clays of eastern Canada where the measured excess pore pressure $(\Delta u)$ is related to the preconsolidation pressure. The data from our five sites and those obtained by the researchers from Laval University support the assumptions that cavity expansion in an elastic-plastic medium adequately approximates the behaviour of lightly to moderately overconsolidated clays. The results also indicate that good quality tests were obtained by both research teams. Tavenas et al. (1982) have pointed out that a correlation in terms of $\Delta u$ and field vane strength is promising, especially if $s_{\mathrm{u}}$ (vane) is calibrated against the behaviour of full-scale structures. These Authors have reported some scatter in field data and observed that $N_{\Delta u}$ depends on the liquidity index (Il). Typical correlations were given as

$$
\begin{aligned}
\Delta u & =N_{\Delta u} s_{\mathrm{u}} \text { with } \\
N \Delta u & =7.9 \pm 0.7 \text { for } 0.8<\mathrm{Il}<2 \\
N \Delta u & =11.7 \pm 2.0 \text { for } \quad \text { II }>2
\end{aligned}
$$

If one assumes that $s_{\mathrm{u}} / \sigma_{\mathrm{p}}{ }^{\prime}$ varies between 0.22 (Mesri, 1975) and 0.37 (from Mayne's contribution) the proposed $\Delta u / \sigma_{\mathrm{p}}^{\prime}$ may vary between 1.7 and 4.3 . This is also confirmed by the data considered in the present discussion since $\Delta u / \sigma_{\mathrm{p}}{ }^{\prime}$ varies between $1 \cdot 86$ and $3 \cdot 20$.

The approach suggested by the Authors is indeed very similar to Mayne's and therefore probably suffers the same limitations. It is thought, however, that the combination of measured tip resistance and induced pore pressure within a simple framework results in a superior sensitivity to property differences for the clay deposits of eastern Canada. This is best demonstrated in figures 15 and 16 of the original paper, where the proposed approach clearly identified layers with different characteristics, whereas analysis based solely on $A u$ would only give the same conclusions if the $q_{1}$ profile were parallel to the pore pressure profile.

The Authors are grateful to Kabir and Lute-

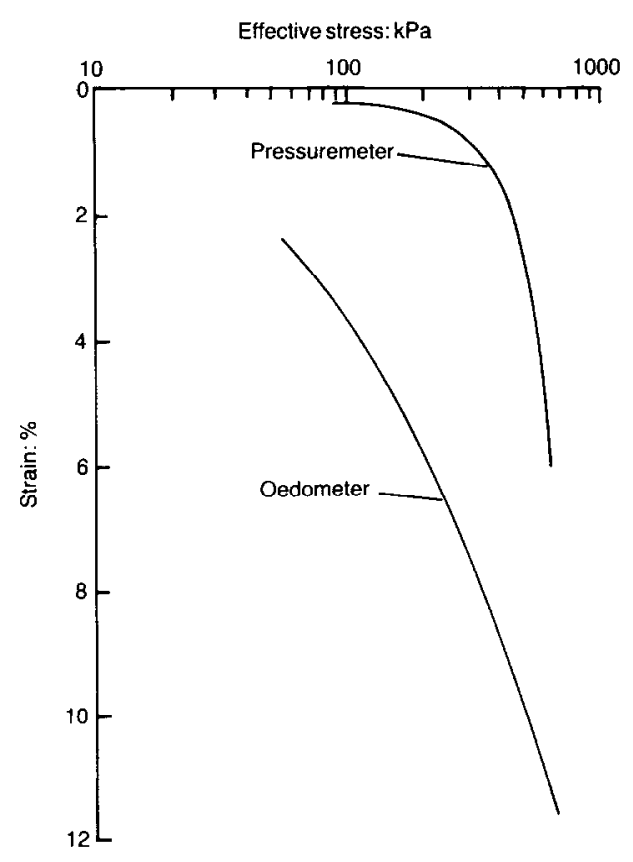

Fig. 13. Plot of strain against logarithm of effective stress for a clayey silt (Law, 1987)

negger for questioning our approach to piezocone data interpretation in overconsolidated soils for OCR $>2$ by presenting additional data on marine clays in northern New York. The results obtained in clays with $\mathrm{OCR}<2$, i.e. test sites MHS and RRC, give strong support to the approach proposed by the Authors. The Writers state that the SLS site is geologically similar to the other two sites, but describe the soil as being a greyish silty clay with a significantly higher sand content. The Authors have experience of clayey silt from Fredericton, New Brunswick which should explain the apparent lack of correlation reported by the Writers. The comparison in Fig. 13 shows that the yield stress and hence the preconsolidation pressure from a self-bored pressuremeter test is significantly higher than that from the laboratory oedometer test. The performance data for a multi-storey building on this soil show that the pressuremeter test results are far more realistic than the laboratory results. This observation explains the softening effect of mechanical disturbance during sampling in clayey silty soils. Additional studies at the SLS site, with particular respect to sample disturbance in siltier soils, is suggested before drawing any conclusions.

It seems that the researchers from the University of British Columbia emphasized the behaviour of cemented Taranto clay and fissured, heavily overconsolidated London clay while the 


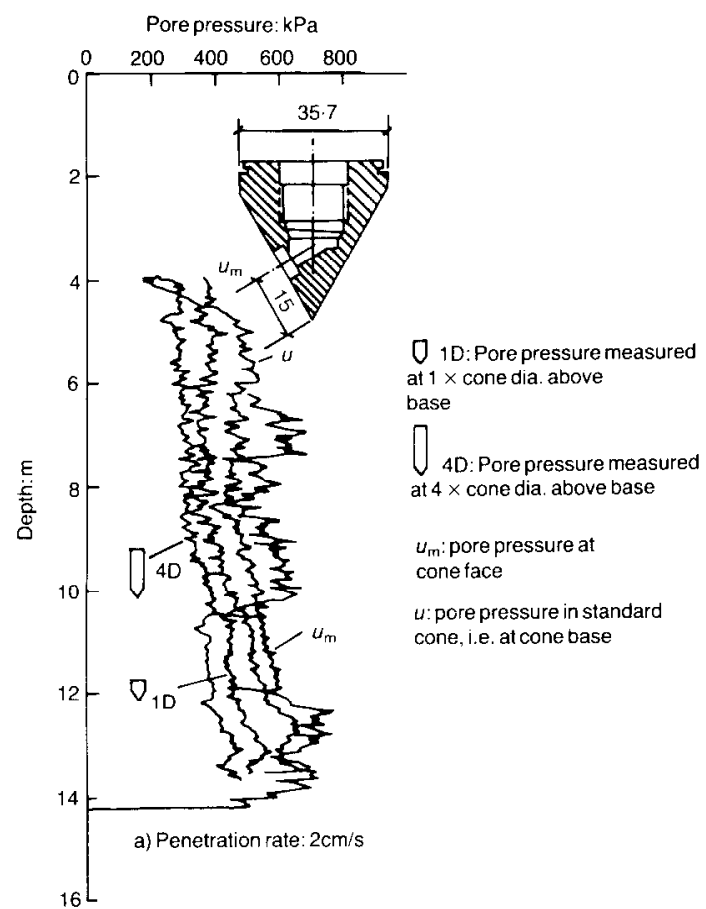

Fig. 14. Comparison between $u_{\mathrm{m}}$ and $u$ at NRCC (Konrad, 1987)

paper specifically addresses piezocone tests in marine clays. Moreover, their discussion refers to 'conceptual' pore pressure distributions during CPTU testing rather than actual measurements. It is appreciated by the Authors that the measurement of pore pressure at the base of the cone is not equal to that in the failure zone during penetration in marine clays. The parameter $\alpha$ was thus introduced to point out this difference, as most piezocones do not record the induced porc pressure at the cone face. However, in marine clays (Fig. 14) the maximum pore pressure during penetration is about 1.2 to 1.3 times the pore pressure obtained at the cone base. Furthermore, it was stated in the Paper that underestimating the pore pressure using $\alpha=1$ and overestimating the friction at the cone mantle by using $M=1$ results in an interpretation that is fairly close to that obtained if the actual values were taken (i.e. $\alpha=1 \cdot 2-1.3$ and $M=0.5-0.75$ ).

Recognizing that $q_{1}$ in soft soils is sensitive to measurement errors, calibration of the tip resistance strain gauge was conducted in the working stress range expected in the field (Konrad, 1987). The use of this in-house calibration rather than the calibration factor specificd by the manufacturer resulted in an error in $q_{1}$ of about $4 \%$ rather than $25 \%$ as suggested by the Writers.

The Writers point out that our equation is vir- tually the same as that proposed by Senneset et al. (1982). It must be stressed that only the component of the measured tip resistance corresponding to undrained cavity expansion is used to derive the proposed correlation. In the Authors approach, it is inferred that the friction on the cone face is a result of effective stresses rather than of undrained shear strength (as proposed by Gibson, 1950; and Ladanyi, 1967). Data obtained for a dam on a thick deposit of marine clay (to be published) show that the proposed approach, taking into account the friction on the cone face, yields an interpretation consistent with vane data, whereas conventional approaches fail to represent the actual behaviour of the clay.

Finally, the Writers conclude that the Authors' proposed relationship between OCR and $\sigma_{\mathrm{yc}}{ }^{\prime} / \sigma_{\mathrm{p}}{ }^{\prime}$ is marginally better than that obtained with the existing $B_{\mathrm{q}}$ correlation. We appreciate these encouragements in the effort to develop rational correlations for in situ testing in marine clays and wish to thank these Writers for their positive comments.

\section{REFERENCES}

Baligh, M. (1986). Undrained deep penetration II : pore pressures. Géotechnique 36, No. 4, 487-501.

Battaglio, M., Bruzzi, D., Jamiolkowski, M. \& Lancellotta, R. (1986). Undrained penetration of saturated clays. Proc. 4th Int. Geotech. Seminar, Singapore.

Campanella, R. G., Robertson, P. K., Gillespie, D. G. \& Grieg, J. (1985). Recent developments in the in situ testing of soils. Proc. 1Ith Int. Conf. Soil Mech. Fdn Engng, San Francisco 1, 849-854.

Campanella, R. G., Robertson, P. K. \& Gillespie, D. (1986). Factors affecting the pore water pressure and its measurement around a penetrating cone. Proc. 39th Can. Geotech. Conj., Ottawa, 291-299.

Campanella, R. G. \& Robertson, P. K. (1988). Current status of the piezocone test. Submitted to lst Int. Symp. Penetration Testing, Orlando.

Gibson, R. E. (1950). Discussion on Wilson, G. The bearing capacity of screw piles and screwcrete cylinders. J. Inst. Civ. Engrs 34, No. 382.

Jamiolkowski, M., Ladd, C. C., Germaine, J. T. \& Lancellotta, R. (1985). New developments in field and laboratory testing of soils. Proc. 1lth Int. Conf. Soil Mech. Fdn Engng, San Francisco 1, 57-153.

Konrad, J.-M. (1987). Piezo-Friction-Cone penetrometer testing in soft clays. Can. Geotech. J. 24, No. 4.

Konrad, J.-M. \& Law, K. T. (1987). Undrained shear strength from piezocone tests. Can. Geotech. J. 24, No. 3, 392-405.

Konrad, J.-M. \& Roy, M. (1987). Bearing capacity of friction piles in marine clay. Géotechnique 37, No. 2, 163-175

Ladanyi, B. (1967). Deep punching of sensitive clays. Proc. 3rd Pan Am. Conf. Soil Mech. Fdn Engng, Caracas 1, 533-546.

Larsson, R. (1980). Undrained shear strength of embankments and foundations on clays. Can. Geotech. I. 17, No. 4, 591-602. 
Law, K. T. (1987). The use of a personal computer for self-boring pressuremeter and piezocone tests. Proc. 40th Can. Geotech. Conf., Regina, 95-103.

Leroueil, S., Tavenas, F., Brucy, F., La Rochelle, P. \& Roy, M. (1979). Behavior of destructured natural clays. J. Geotech. Engng Div. Am. Soc. Civ. Engrs 105, GT6, 759-778.

Lunne, T., Christoffersen, H. P. \& Tjelta, T. I. (1985). Engineering use of piezocone data in North Sea clays. Proc. 11th Int. Conf. Soil Mech. Fdn Engng, San Francisco 4, 907-912.

Lutenegger, A. J. \& Kabir, M. G. (1987). Pore pressures generated by two penetrometers in clay. Report No. 87-2, Dept Civil and Environmental Engng, Clarkson University.

Mayne, P. W. (1987). Determining preconsolidation stress and penetration pore pressures from DMT contact pressures. Geotech. Testing J. 10, No. 3.

Mayne, P. W. \& Bachus, R. C. (1987). Profiling OCR in clays by piezocone soundings. Submitted to 1st Int. Symp. Penetration Testing, Orlando.

Mesri, G. (1975). Discussion on New design procedure for stability of soft clays. J. Geotech. Engng Div. Am. Soc. Civ. Engrs 101, GT4, 409-412.

Randolph, M., Carter, J. \& Wroth, C. P. (1979). Driven piles in clay. Géotechnique 29, No. 4, 361-393.

Robertson, P. K. \& Campanella, R. (1983). Interpretation of cone penetration tests, part II: clay. Can. Geotech. J. 20, No. 4, 734-745.

Robertson, P. K., Campanella, R. G., Gillespie, D. G. \& Grieg, J. (1986). Use of piezometer cone data. In situ testing in geotechnical engineering, Am. Soc. Civ. Engrs Spec. Conf. INSITU 86, Blacksburg, 12631280.

Roy, M., Tremblay, M., Tavenas, F. \& La Rochelle, P. I. (1982) Development of pore pressures in quasistatic penetration tests in sensitive clay. Can. Geotech. J. 19, No. 2, 124-138.

Roy, M., Tremblay, M., Tavenas, F. \& La Rochelle, P. L. (1982). Development of a quasi-static piezocone apparatus. Can. Geotech. J. 19, No. 2, 180-188.

Senneset, K., Janbu, N. \& Svanø, G. (1982). Strength and deformation parameters from cone penetration tests. Proc. 2nd Euro. Symp. Penetration Testing, Amsterdam, 863-870.

Sully, J. P., Campanella, R. G. \& Robertson, P. K. (1987). Overcunsolidation ratio of clays from penetration pore pressures. Private Communication.

Sully, J. P., Campanella, R. G., Robertson, P. K. \& Gillespie, D. (1988). Interpretation of penetration pore pressures to evaluate stress history in clays. Submitted to Ist Int. Symp. Penetration Testing, Orlando.

Tavenas, F. (1981). Advantages and limitations of the piczoconc. Proc. I0th Int. Conf. Soil Mech. 2, 769 773.

Tavenas, F., Leroueil, S. \& Roy, M. (1982). The piezocone test in clays: use and limitations. Proc. 2nd Euro. Conf. Penetration Testing, Amsterdam 2, 889-894.

Wroth, C. P. (1984). The interpretation of in situ soil tests. Géotechnique 34, No. 4, 449-489. 